\title{
Effects of Irritability on Craving before and after Cue Exposure in Abstinent Alcoholic Inpatients: Experimental Data on Subjective Response and Heart Rate
}

\author{
Sonnig S.W. Chiang Christian G. Schuetz Michael Soyka \\ Psychiatric Hospital of Munich University, Munich, Germany
}

\section{Key Words}

Alcohol · Alcoholism · Craving · Cue exposure . Irritability

\begin{abstract}
Objective: Irritability is often linked with problem drinking. The aim of this study is to examine the possible influence of irritability on craving induced by a cue-exposure paradigm. Methods: 30 male abstinent alcoholic inpatients of the Psychiatric Hospital of Munich University, Germany gave answers to a series of personality questionnaires. Results of this study concerning the impact of aggressivity on craving for alcohol has recently been published. In this study, the subjects were subdivided into a low- and a high-irritable group based on their scores on the irritability subscale of the Buss-Durkee Hostility Inventory and were exposed to alcohol cues. Craving was measured by means of the Alcohol Craving Questionnaire (ACQ) and Visual Analogue Scales (VAS). The heart rate was also assessed throughout the whole process. ANCOVA for repeated measurement was employed to evaluate the data - irritability disposition as the between-subject factor and the experimental manipulation (absence vs. presence of alcohol cues) as the within-subject factor. Results: Major findings are: (1) main effects of irritability on 'emotionality', 'purposefulness', and 'expectancy' of the ACQ as well as
\end{abstract}

\section{KARGER}

Fax +41613061234 E-Mail karger@karger.ch www. karger.com
(C) 2002 S. Karger AG, Basel

0302-282X/02/0463-0150\$18.50/0

Accessible online at:

www. karger.com/nps on 'craving for alcohol' of the VAS were significant; (2) cue exposure also exerted a significant main effect on 'craving for alcohol' of the VAS and on the heart rate after the presentation of alcohol cues; (3) on 'compulsivity' of the ACQ and 'intention to alcohol intake' of the VAS; there was a significant interaction between irritability and cue exposure. The high-irritable alcoholics, compared with their statements in the baseline, tended to report a higher control over alcohol intake and a lower intention to alcohol use after cue exposure. However, after confrontation with alcohol stimuli, their low-irritable counterparts reported a much lower control and a slightly higher intention than they did in the baseline. Conclusions: The results of this study indicate that induced craving in hospitalized alcohol addicts probably varies with the magnitude of their irritability; it might make patients more aware of their vulnerability to alcohol, help them develop more differential coping strategies and improve medical therapy against alcohol craving.

Copyright $\odot 2002$ S. Karger AG, Basel

\section{Introduction}

A significant role of craving has been recognized in the mechanism of addiction [Ciccocioppo, 1999; Newlin, 1992; Sinha and O’Malley, 1999] despite its controversial

Dr. Sonnig S.W. Chiang

Psychiatric Hospital of Munich University, Nussbaumstrasse 7

D-80336 Munich (Germany)

Tel. +49 8951602777 , Fax +49 8951605617

E-Mail Sonnig.Chiang@psy.med.uni-muenchen.de 
definition [Flannery et al., 2001; Meyer, 2000; Anton, 1999; Pickens and Johanson, 1992; Kozlowski et al., 1989; Potgieter et al., 1983]; i.e. it is an internal cue, possibly precipitating relapse [Naranjo and Kadlec, 1991; Markou et al., 1993; Norregaard et al., 1993]. The source of craving is believed to reside rather in the personality of the addicts than in their tissues [Ausubel, 1983] and personality variables may have a major impact on the development of craving [Preuss et al., 1999]. The salience of personality in developing alcoholism was also indicated by various authors [Cloninger et al., 1988; Gunderson and Philips, 1995; Sher and Trull, 1994; Prescott et al., 1997], although the relationship between craving and personality had been rarely investigated in the past. Only Gilbert [1997] attempted to integrate personality features as important intervening factors with a possible impact on craving in his Situation-Trait-Adoptive-Response Model. This model posits that situational and trait factors could influence drug urges/craving, drug choice, affect modulation of drugs, abstinence moods, drug use as well as relapse and hypothesizes that a set of relatively lateralized and localized brain systems underlie bioinformation processing associated with these processes, states, and traits. Our recent findings likewise point to a strong association between aggressivity and craving [Chiang et al., 2001].

It was indicated by Lewis et al. [1985] over a decade ago that excessive irritability was closely associated with alcoholism. Irritability, defined as the propensity to experience and express anger following actual or perceived provocation and as an inclination toward behavioral disinhibition, is a component of the liability to alcohol and drug abuse [Tarter et al., 1995]. The trait irritability is among the most salient features of an antisocial personality disorder [Lewis et al., 1985; Moss et al., 1990; Verheul et al., 1998] and encompasses both the emotional and aggressive facets of dysregulation [Tarter et al., 1995; Chiang et al., 2001].

Longitudinal data indicate that excessive irritability precedes problem drinking [Lewis et al., 1985]. Antisocial symptoms including excessive irritability were reported to relate positively to the extent of adult alcohol use [Robins, 1970]. Relevant literature likewise shows: (1) irritability could predict alcohol use. It is associated with drug and alcohol use as a coping response to problems in adolescents. Paternal history of substance abuse disorder may be less essential than dispositional factors, such as irritability, for predicting the development of drug and alcohol abuse [Tarter et al., 1995]. (2) Irritability is a typical characteristic for, at least, a subgroup of alcoholics [Nerviano and Gross, 1983]. It is described as a more frequent fea- ture of drug and alcohol abusers with childhood conduct disorder and adult antisocial personality disorder [Cottler et al., 1995] and is considered a liability trait for type 2 alcoholics [Cloninger et al., 1981]. Renson et al. [1978] compared the personality differences between violent and nonviolent alcohol abusers on the Buss-Durkee Hostility Inventory (BDHI) and suggested that violent alcoholics scored significantly higher than controls on the total hostility score and on subscales measuring assault, irritability, verbal hostility, indirect hostility, and resentment. The differences in those aspects between violent and nonviolent alcoholics were, however, not significant. (3) Enhanced irritability is also a substantial feature for the offspring of alcoholics. Tomori [1994] examined personality traits frequently encountered in male and female adolescents who were from families with at least one alcoholic parent and found that irritability belongs to one of the important dispositions which differentiate children of alcoholics from those of nonalcoholics.

So far, except for our previous report concerning the impact of aggressivity on craving for alcohol [Chiang et al., 2001], there has not been found any other experimental evidence indicating a relationship between craving for alcohol and personality. From a conceptual point of view, irritablity may be a normal mood or personality trait, while increased levels of irritability may be symptomatic of certain disorders [Snaith and Tylor, 1985] or predispose to others, e.g. alcoholism. Aggression is a personality trait within the normal range, but, in contrast to irritability, also represents a clear psychopathological symptom. As a state, irritability can be viewed as a mood state which is independent of other moods of depression and anxiety. As a trait, it may still be distinguished from aggression and violent behavior [Snaith and Taylor, 1985], although showing an overlap with aggression as indicated above, e.g. by the subscales of the BDHI. In particular, there is an overlap with autoaggression, with special relevance to suicidality. There may be a broad spectrum of hostility ranging from irritability to violent behavior. Apparently, a relation between suicidal behavior and the tendency to impulsive aggression can be observed [Brent et al., 1996]. Irritability but not aggression is frequent in depression, anxiety and Alzheimer's disease [Mega et al., 1996]. It can also be found in personality disorders [Svanborg et al., 1999]. As mentioned above, irritability is one of the 8 scores that are termed 'different kinds of hostility' in the $\mathrm{BDHI}$, the primary psychodiagnostic research instrument in this study. Nevertheless, it seems worthwhile to investigate irritability separately because aggression may be differently related to alcohol craving due to other facets, such 
as verbal hostility, resentment, or assault which in other studies have been shown to contribute separate variance, which is not identical with that of irritability.

Our study attempted to explore the possible influences of a series of personality features on craving and their interactions with various alcohol cues with which the alcoholics will be confronted after discharge from hospital. We induced craving by presenting alcohol cues of 3 different modalities in weaned alcoholic inpatients in a laboratory setting and to examine the extent to which craving depends on the irritability and other tendencies of alcohol addicts in order to find out further differential indicators for medical as well as psychological therapy. This report regards the effects of irritability and its interactions with alcohol stimuli in hospitalized alcoholics.

\section{Methods}

\section{Subjects}

Details on sample acquisition and personality questionnaires have been given elsewhere [Chiang et al., 2001]. A total of 36 male alcoholic inpatients of the Psychiatric Hospital of Munich University, Germany took part in this study. Six of them dropped out before the experiment started. Significant criteria included: (1) fulfilled criteria for alcohol dependence according to DSM-IV [American Psychiatric Association, 1994] and ICD-10 [World Health Organization, 1994], (2) a completed detoxification, and (3) a minimum abstinence duration of 1 week. Exclusion criteria were abuse of/dependence on psychotropic substances other than nicotine and alcohol, major psychiatric disorders other than alcoholism, such as schizophrenia, affective disorders, suicidal risk, cognitive dysfunction, severe medical illness, and current use of psychotropic agents (neuroleptics, antidepressants, and anxiolytics). Those who had difficulties in understanding written and spoken German were excluded as well.

\section{Design}

Irritable inclination of the subjects and experimental manipulation (absence or presence of alcohol stimuli) were independent variables. The classification of the subjects was done by means of cluster center analysis; they were classified into 2 most heterogeneous groups according to their propensity to irritability - a high- [mean $(\mathrm{M})=$ 8.07; standard deviation $(\mathrm{SD})=1.38$ ] and a low-irritable group $(\mathrm{M}=$ $3.5 ; \mathrm{SD}=1.32$ ). Dependent variables contained a physiological indicator (heart rate) and psychological parameters (self-rated craving before and after cue exposure). The heart rates were measured continuously throughout the whole baseline as well as throughout the whole exposure phase. A Highest-Heart-Rate (HHR) Paradigm was employed to assess the heart rate of subjects; the HHR obtained in each phase (baseline vs. cue exposure) was regarded as the objective reaction in the corresponding period (baseline vs. cue exposure). Because the mean ages of the high- and low-irritable subgroup (41.3 vs. 47.3 years $)$ were significantly different from each other $(p=0.03)$, the effects of irritability and alcohol cues on craving and heart rate were analyzed by using the factor 'age' as a covariate. Moreover, for the variance heterogeneity of the high- and low-irritable alcoholic group in all Visual Analogue Scale (VAS) variables, nonparametric tests (Mann-Whitney $\mathrm{U}$ tests) and $\mathrm{t}$ tests for independent variables with unequal group variances were conducted to detect the group differences of all VAS variables. The data were evaluated by using ANCOVA for repeated measurements (SPSS 9.0); the between-subject factor was irritability (low vs. high) and the within-subject factor was the experimental manipulation (baseline vs. cue exposure).

\section{Materials}

The Alcohol Withdrawal Scale and the Structured Clinical Interview for DSM-IV (SCID, German version) [Wittchen et al., 1997] were conducted to exclude those patients who still experienced alcohol withdrawal or who suffered from psychiatric disorders other than alcoholism and nicotine. The medical histories of participants were extracted from the patients' files. The subscale 'irritability' of the BDHI Inventory (German version) [Kornadt, 1982] was employed to measure irritability propensity. It consists of 11 yes/no questions with a score ranging from 0 to 11 . The Alcohol Craving Questionnaire (ACQ, German version) [Schuetz et al., 1997] is a 7-point scale; it contains four dimensions: emotionality (EMOT), purposefulness (PURP), compulsivity (COMP) and expectancy (XPCT). EMOT measures craving associated with negative emotions, PURP the intention to drink alcohol, XPCT the perceived positive effects that are linked to alcohol use and COMP represents the feeling of loss of control over alcohol ingestion. Each dimension contains 3 questions; for each dimension, the score could vary from a minimum of 3 to a maximum of 21. For EMOT, PURP, and XPCT, it means 'the higher the score, the stronger the craving'. However, a higher score on COMP means a stronger control over alcohol use, that is, less craving for alcohol. The ACQ had been developed and validated by Tiffany et al. [1995]; it belongs to one of the first systematically contrived alcohol craving scales. VAS is a $100-\mathrm{mm}$ scale, which is frequently used in the clinical area to measure craving; however, it is not standardized and its reliability remains unknown. It could be differently combined with representative questions, depending on various research goals. In this study, 6 questions were included: drinking intention, craving for alcohol, enjoy drinking alcohol, probability to result in alcohol use, being depressed, and being nervous. Each measure obtained for every single question of VAS could vary between 0 and 100. Finally, because of the close association between alcohol use and anxiety as well as the significant correlation between irritability and aggressivity, the data from the Trait Anxiety Inventory (STAI, German version) [Laux et al., 1981] and from the physical aggression subscale of the BDHI Inventory [Kornadt, 1982] were also assessed in the screening phase. In addition, the State-Anxiety Subscale of the STAI and the Profile of Mood States (POMS, German version) [McNair et al., 1981] were conducted before and after cue exposure in order to measure state anxiety as well as the mood changes. BDHI, ACQ, VAS, STAI and POMS are computerized, which ameliorates the reliability of the measurement by reducing some unsystematic mistakes, such as missing data and double-marking.

\section{Procedure}

The study was divided into three phases: a screening, a habituation and an experimental phase. Those patients who had completed detoxification and whose Alcohol Withdrawal Scale scores were less than 4 were chosen in the screening phase. After a written informed consent was obtained, an interview using SCID was conducted. Then, a series of personality questionnaires including the BDHI (irritability and physical aggression) and the STAI (trait anxiety) were rated by the subjects. 
Table 1. Means and standard deviations of demographic variables for both the low and high irritability group

\begin{tabular}{|c|c|c|c|c|c|}
\hline \multirow[t]{3}{*}{ Group statistics } & \multicolumn{4}{|c|}{ Tendency to irritability } & \multirow[t]{3}{*}{$\mathrm{p}$ ( $\mathrm{t}$ test) } \\
\hline & \multicolumn{2}{|c|}{$\operatorname{high}(n=14)$} & \multicolumn{2}{|c|}{ low $(n=16)$} & \\
\hline & M & SD & M & SD & \\
\hline Age, years & 41.29 & 7.62 & 47.31 & 6.54 & $0.03^{1}$ \\
\hline Detoxifications, $\mathrm{n}$ & 2.07 & 1.77 & 1.56 & 0.73 & 0.30 \\
\hline Abstinence duration, days & 22.79 & 17.25 & 19.94 & 8.79 & 0.57 \\
\hline Drinking amount, drinks/day & 29.79 & 13.03 & 24.28 & 7.62 & 0.18 \\
\hline Education, years school & 10.29 & 3.56 & 11.13 & 4.22 & 0.56 \\
\hline
\end{tabular}

The experiment took place between 5 and 9 p.m. when most subjects usually consumed alcohol. After attaching a pulse oximeter, the subjects were first required to close their eyes and to relax for $3 \mathrm{~min}$ until their actual pulse approximated to normal values $( \pm 5)$ which were obtained by a nurse in the morning of the experimental day. Then, the data for ACQ, VAS, POMS, STAI (state scale) and the peak heart rate in this phase were collected as baseline measurements. The second section of the experiment was a cue exposure phase: the subjects were asked to imagine a scene of their life as an alcoholic for $3 \mathrm{~min}$ and then they were exposed to an alcohol-related film. Three minutes after the film demonstration, a bottle of their favorite beer, an opener, an empty beer glass, and 3 empty beer bottles were sited on the table standing right in front of them within their eyesight. Another $3 \mathrm{~min}$ after that, they had to open the beer and pour it into the empty beer glass at the request of the experimenter. Next, they were asked to hold the beer, if possible, close to their nose without touching it and to smell it for another $3 \mathrm{~min}$. Finally, they had to put the beer on the table within their vision and answered the questions of ACQ, VAS, STAI and POMS for the second time. Each time, the questions of ACQ, VAS, STAI and POMS were presented randomly on a computer screen in order to control for the memory and habituation effect because the tests were shown twice within $1 \mathrm{~h}$. Additionally, the way the subjects acted (e.g. remarkable movements) and the accompanied heart rate and the heart rate shortly after movements in both the baseline and cue exposure phase were recorded. After the experiment was finished, the subjects were interviewed concerning their feelings towards the different alcohol stimuli.

\section{Results}

The demographic data (including age, number of detoxifications, and abstinence durations) of those who completed the experiments $(\mathrm{n}=30)$ and those who dropped out $(n=6)$ did not show any statistically significant differences except for their educational level and daily alcohol intake. The 6 dropouts were less educated $(8.8$ years) and consumed explicitly more alcohol (56.5 standard drinks/day) in the preceding week before admission to the clinic. The mean age of the 30 subjects was 44.5 years $(\mathrm{SD}=7.6$; range $32-58)$ and the mean number of hospitalized medical detoxifications was $1.8(\mathrm{SD}=1.3)$. They had visited school for 10.7 years $(\mathrm{SD}=3.9)$. Two $(6.7 \%)$ of the 30 subjects were unemployed at the time of participating in the study. Eighteen $(60 \%)$ were single when they were recruited. On average, they drank 26.9 standard drinks $(\mathrm{SD}=10.7)$ per day 1 week before their admission to the clinic and had been abstinent for 21.3 days $(\mathrm{SD}=13.3)$. The demographic data of both the lowand high-irritable subgroup are listed in table 1. No statistically significant differences were shown except for mean age, which achieved a statistical significance level of 0.05 ; the high-irritable alcohol addicts $(\mathrm{M}=41.29$ years old $)$ were significantly younger than the low-irritable ones $(\mathrm{M}=47.31$ years old $)$.

Tables 2 and 3 illustrate the data of state and trait anxiety (STAI), physical aggression (BDHI), and the scores on the POMS for both groups; the high- and low-irritable group did show statistically very significant differences on 'state anxiety' of the STAI ( $p=0.006$ vs. $p=0.01)$, on 'confusion' of the POMS ( $p=0.01$ vs. $p=0.005)$ at baseline as well as after cue exposure, on 'trait anxiety' of the STAI ( $p<0.0001)$, and on 'physical aggression' of the BDHI $(p=0.008)$. In addition, high-irritable alcoholics reported a more depressive mood (POMS) than did the low-irritable ones; however, solely that examined at baseline reached a significance level of 0.05 .

The results for the craving measurements (ACQ and VAS) at baseline and after cue exposure, $t$ tests/MannWhitney U tests (VAS), and the outcomes of ANCOVA (ACQ and VAS) are summarized in tables 4-6. The minor differences between the outcomes of ANCOVA and those of $t$ tests/Mann-Whitney $U$ tests might result from the fact that (1) the interactions of both variables (irritability and presence/absence of alcohol cues), (2) tests for the dependent variables (baseline and exposure data are from the 
same sample) as well as the independent variable (low and high irritability), and (3) the effect of significantly different ages between both groups was simultaneously taken into account in the ANCOVA analysis, but they were not the case in $t$ tests/Mann-Whitney $U$ tests.

The findings of the ACQ revealed that irritability, regardless of the presence of alcohol cues, had a clear impact on the following dimensions of craving: EMOT $[F(1,29)=9.54 ; p=0.005], \operatorname{PURP}[F(1,29)=10.55 ; \mathrm{p}=$ $0.003]$, and XPCT $[F(1,29)=6.03 ; p=0.02]$. Together with cue exposure, the irritability disposition also exhib- ited a significant interactive effect on COMP of the ACQ $[F(1,29)=5.11 ; p=0.03]$ (fig. 1). Despite the experimental manipulations, the alcoholic patients with high irritability declared that (1) they had significantly stronger craving which is associated with negative affects (EMOT), that (2) they significantly strongly agreed with that they planned to drink alcohol as soon as possible (PURP) and that (3) they would feel less tense, less restless, and less nervous if they could drink alcohol (XPCT). After cue exposure, the magnitude of these 3 dimensions of the ACQ (EMOT, PURP, XPCT) in the high-irritable alcohol
Table 2. Tendency to irritability (BDHI), state and trait anxiety (STAI) and physical aggression (BDHI) of the low (L) and high (H) irritability group at baseline (B) measurement (irritability, state and trait anxiety as well as aggression) and after cue exposure (E; only state anxiety)
Table 3. Profile of mood states (POMS) of the low $(\mathrm{L})$ and high $(\mathrm{H})$ irritability group at baseline (B) measurement and after cue exposure (E)

\begin{tabular}{|c|c|c|c|c|c|}
\hline \multirow{3}{*}{$\begin{array}{l}\text { Anxiety/aggression, } \\
\text { group statistics }\end{array}$} & \multicolumn{4}{|c|}{ Tendency of irritability } & \multirow{3}{*}{$\begin{array}{l}p(t \text { test) } \\
\text { H vs. L }\end{array}$} \\
\hline & \multicolumn{2}{|c|}{$\operatorname{high}(n=14)$} & \multicolumn{2}{|c|}{ low $(n=16)$} & \\
\hline & M & SD & M & SD & \\
\hline Irritability & 8.07 & 1.38 & 3.5 & 1.32 & $0.000^{* * *}$ \\
\hline \multicolumn{6}{|l|}{ State anxiety } \\
\hline B & 47.43 & 9.36 & 38.19 & 7.66 & $0.006^{* *}$ \\
\hline $\mathrm{E}$ & 45.79 & 8.95 & 38.13 & 6.91 & $0.01^{* *}$ \\
\hline p (B vs. E) & 0.53 & & 0.95 & & \\
\hline Trait anxiety & 56.50 & 12.24 & 40.81 & 9.14 & $0.000 * * *$ \\
\hline Physical aggression & 6.36 & 1.95 & 4.31 & 1.99 & $0.008 * *$ \\
\hline
\end{tabular}

\begin{tabular}{|c|c|c|c|c|c|}
\hline \multirow[t]{3}{*}{ POMS } & \multicolumn{4}{|c|}{ Tendency of irritability } & \multirow[t]{3}{*}{$\mathrm{p}(\mathrm{H}$ vs. $\mathrm{L})$} \\
\hline & \multicolumn{2}{|c|}{$\operatorname{high}(n=14)$} & \multicolumn{2}{|c|}{ low $(n=16)$} & \\
\hline & M & SD & M & SD & \\
\hline \multicolumn{6}{|l|}{ Confusion } \\
\hline baseline & 10.93 & 4.67 & 7.38 & 1.09 & $0.01 *$ \\
\hline exposure & 11.43 & 4.07 & 7.67 & 1.40 & $0.005^{* *}$ \\
\hline $\mathrm{p}$ (B vs. E) & 0.69 & & 0.48 & & \\
\hline \multicolumn{6}{|l|}{ Fatigue } \\
\hline baseline & 13.93 & 7.11 & 11.00 & 6.66 & 0.51 \\
\hline exposure & 13.36 & 5.73 & 11.73 & 7.27 & 0.26 \\
\hline p (B vs. E) & 0.72 & & 0.26 & & \\
\hline \multicolumn{6}{|l|}{ Depression } \\
\hline baseline & 23.86 & 8.85 & 18.38 & 5.08 & $0.05^{*}$ \\
\hline exposure & 23.07 & 9.77 & 18.33 & 4.19 & 0.11 \\
\hline $\mathrm{p}(\mathrm{B}$ vs. $\mathrm{E})$ & 0.73 & & 0.60 & & \\
\hline \multicolumn{6}{|l|}{ Vigor } \\
\hline baseline & 17.21 & 6.28 & 19.06 & 5.57 & 0.40 \\
\hline exposure & 16.43 & 5.87 & 18.27 & 6.03 & 0.41 \\
\hline $\mathrm{p}(\mathrm{B}$ vs. E) & 0.60 & & 0.51 & & \\
\hline
\end{tabular}

$* \mathrm{p}<0.05 ; * * \mathrm{p}<0.01$. 
addicts was enhanced, whereas those of the alcohol addicts with low irritability was reduced. The control over alcohol use (COMP) of the alcoholics with high irritability was smaller than that of those subjects with low irritability at baseline; however, the control over alcohol intake after exposure to alcohol stimuli increased to an extent that it became even stronger than that of their low-irritable counterparts, while that of the low-irritable alcoholic patients was reduced. The dimension COMP of the ACQ consists of 3 questions concerning 'plans to alcohol intake', 'enjoy alcohol consumption', and 'loss of control over alcohol use'.

Fig. 1. The interactive effect between irritability and cue exposure on the dimension COMP of the ACQ. The result presented here is corrected for age.

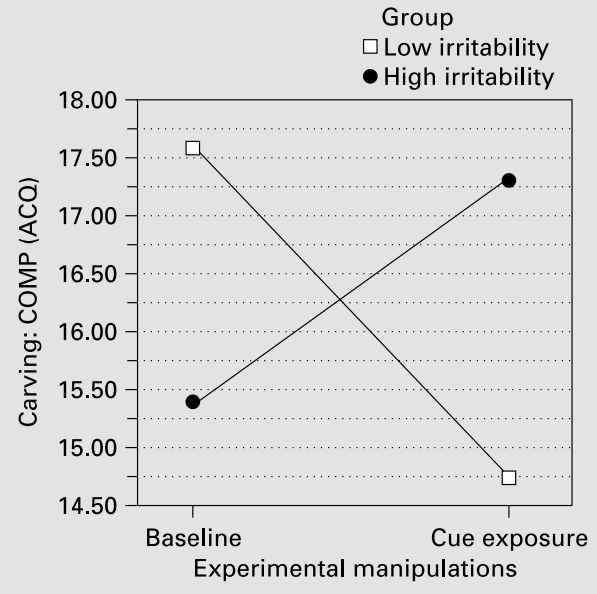

Table 4. Means and standard deviations of the craving variables for both the low and high irritable group

\begin{tabular}{|c|c|c|c|c|c|c|c|c|}
\hline & \multicolumn{4}{|c|}{ Baseline } & \multicolumn{4}{|c|}{ Experiment } \\
\hline & \multicolumn{2}{|c|}{$\operatorname{high}(n=14)$} & \multicolumn{2}{|c|}{ low $(n=16)$} & \multicolumn{2}{|c|}{$\operatorname{high}(n=14)$} & \multicolumn{2}{|c|}{ low $(n=16)$} \\
\hline & M & SD & M & $\mathrm{SD}$ & M & SD & M & SD \\
\hline EMOT & 7.29 & 3.20 & 4.56 & 2.19 & 7.79 & 5.54 & 4.06 & 1.34 \\
\hline PURP & 7.57 & 4.82 & 4.50 & 1.90 & 7.93 & 4.71 & 3.75 & 1.29 \\
\hline COMP & 15.36 & 4.83 & 17.63 & 4.46 & 17.43 & 2.71 & 14.63 & 5.30 \\
\hline XРCT & 9.64 & 4.57 & 6.75 & 4.30 & 9.79 & 5.10 & 4.94 & 3.45 \\
\hline VAS-intent & 4.93 & 6.50 & 2.83 & 1.30 & 3.74 & 3.93 & 2.53 & 0.60 \\
\hline VAS-crave & 17.52 & 25.38 & 3.13 & 2.42 & 21.09 & 29.20 & 2.53 & 0.60 \\
\hline VAS-enjoy & 11.73 & 21.59 & 4.61 & 6.65 & 20.41 & 30.42 & 3.87 & 4.83 \\
\hline VAS-drink & 8.16 & 13.33 & 2.68 & 1.19 & 9.35 & 13.80 & 2.53 & 0.60 \\
\hline VAS-depre & 20.41 & 29.34 & 6.40 & 6.55 & 25.85 & 34.17 & 8.33 & 20.85 \\
\hline VAS-nerv & 35.20 & 35.76 & 15.63 & 15.26 & 28.06 & 32.57 & 9.97 & 16.04 \\
\hline Pulse/min & 80.36 & 7.26 & 86.19 & 11.38 & 88.36 & 7.75 & 93.44 & 12.39 \\
\hline
\end{tabular}

Score range for ACQ: 3-21; for VAS: 0-100.

Table 5. Significant of the differences between the high- and low-irritable alcohol addicts in the VAS before and after cue exposure

\begin{tabular}{|c|c|c|c|c|c|c|c|c|c|c|c|c|}
\hline & \multicolumn{2}{|c|}{ VAS-intent } & \multicolumn{2}{|c|}{ VAS-crave } & \multicolumn{2}{|c|}{ VAS-enjoy } & \multicolumn{2}{|c|}{ VAS-drink } & \multicolumn{2}{|c|}{ VAS-depres } & \multicolumn{2}{|c|}{ VAS-nerv } \\
\hline & B & $\mathrm{E}$ & B & $\mathrm{E}$ & $\mathrm{B}$ & $\mathrm{E}$ & B & $\mathrm{E}$ & $\mathrm{B}$ & $\mathrm{E}$ & B & $\mathrm{E}$ \\
\hline t-test & 0.25 & 0.27 & $0.05^{*}$ & $0.03 *$ & 0.25 & 0.06 & 0.15 & 0.09 & $0.05^{*}$ & 0.29 & 0.08 & 0.08 \\
\hline M-W & 0.61 & 0.70 & $0.05^{*}$ & $0.03 *$ & 0.58 & 0.22 & 0.29 & 0.14 & 0.22 & 0.70 & 0.22 & $0.01 * *$ \\
\hline
\end{tabular}

Summary of results ( $\mathrm{p}$ values) from $\mathrm{t}$ tests for independent variables with unequal group variance, and from Mann-Whitney U tests (M-W). $\mathrm{B}=$ Baseline; $\mathrm{E}=$ cue exposure. ${ }^{*} \mathrm{p}<0.05 ; * * \mathrm{p}<0.01$. 
Table 6. The main effect of irritability and the interaction between irritability and cue exposure

\begin{tabular}{|c|c|c|c|c|c|c|c|}
\hline Questionnaire & Dimension & Source & Sum of Squares & d.f. & Mean of squares & $\mathrm{F}$ & Significance \\
\hline \multirow[t]{12}{*}{ ACQ } & \multirow[t]{3}{*}{ EMOT } & $\mathrm{BE}$ & 0.69 & 1 & 0.69 & 0.09 & 0.76 \\
\hline & & Irr & 150.05 & 1 & 150.05 & 9.54 & $0.005^{* *}$ \\
\hline & & $\mathrm{BE} \times \mathrm{Irr}$ & 2.04 & 1 & 2.04 & 0.28 & 0.60 \\
\hline & \multirow[t]{3}{*}{ COMP } & $\mathrm{BE}$ & 1.65 & 1 & 1.65 & 0.12 & 0.73 \\
\hline & & Irr & 0.41 & 1 & 0.41 & 0.02 & 0.90 \\
\hline & & $\mathrm{BE} \times \mathrm{Irr}$ & 69.41 & 1 & 69.41 & 5.11 & $0.03 *$ \\
\hline & \multirow[t]{3}{*}{ PURP } & $\mathrm{BE}$ & 2.50 & 1 & 2.50 & 2.10 & 0.16 \\
\hline & & Irr & 233.30 & 1 & 233.30 & 10.55 & $0.003^{* *}$ \\
\hline & & $\mathrm{BE} \times \mathrm{Irr}$ & 1.60 & 1 & 1.60 & 1.34 & 0.26 \\
\hline & \multirow{3}{*}{ XPCT } & $\mathrm{BE}$ & $2.26 \times 10^{-4}$ & 1 & $2.26 \times 10^{-4}$ & 0.00 & 1.00 \\
\hline & & $\operatorname{Irr}$ & 187.30 & 1 & 187.30 & 6.03 & $0.02 *$ \\
\hline & & $\mathrm{BE} \times \mathrm{Irr}$ & 10.64 & 1 & 10.64 & 1.27 & 0.27 \\
\hline \multirow[t]{18}{*}{ VAS } & \multirow[t]{3}{*}{ VAS-intent } & $\mathrm{BE}$ & 14.50 & 1 & 14.50 & 5.59 & $0.03^{*}$ \\
\hline & & $\operatorname{Irr}$ & 74.45 & 1 & 74.45 & 3.12 & 0.09 \\
\hline & & $\mathrm{BE} \times \mathrm{Irr}$ & 10.97 & 1 & 10.97 & 4.22 & $0.05^{*}$ \\
\hline & \multirow[t]{3}{*}{ VAS-crave } & $\mathrm{BE}$ & 532.95 & 1 & 532.95 & 4.23 & $0.05^{*}$ \\
\hline & & Irr & $3,139.32$ & 1 & $3,139.32$ & 5.43 & $0.03^{*}$ \\
\hline & & $\mathrm{BE} \times \mathrm{Irr}$ & 2.87 & 1 & 2.87 & 0.02 & 0.88 \\
\hline & \multirow[t]{3}{*}{ VAS-enjoy } & $\mathrm{BE}$ & 40.26 & 1 & 40.26 & 0.19 & 0.67 \\
\hline & & Irr & $1,739.76$ & 1 & $1,739.76$ & 3.54 & 0.07 \\
\hline & & $\mathrm{BE} \times \mathrm{Irr}$ & 225.47 & 1 & 225.47 & 1.05 & 0.32 \\
\hline & \multirow[t]{3}{*}{ VAS-drink } & $\mathrm{BE}$ & 13.85 & 1 & 13.85 & 1.27 & 0.27 \\
\hline & & Irr & 541.23 & 1 & 541.23 & 3.25 & 0.08 \\
\hline & & $\mathrm{BE} \times \mathrm{Irr}$ & 0.95 & 1 & 0.95 & 0.09 & 0.77 \\
\hline & \multirow[t]{3}{*}{ VAS-depres } & $\mathrm{BE}$ & 155.48 & 1 & 155.48 & 0.30 & 0.59 \\
\hline & & Irr & $2,250.92$ & 1 & $2,250.92$ & 3.21 & 0.08 \\
\hline & & $\mathrm{BE} \times \mathrm{Irr}$ & 4.00 & 1 & 4.00 & 0.01 & 0.93 \\
\hline & \multirow[t]{3}{*}{ VAS-nerv } & $\mathrm{BE}$ & 237.94 & 1 & 237.94 & 0.65 & 0.43 \\
\hline & & Irr & $3,256.29$ & 1 & $3,256.29$ & 3.20 & 0.09 \\
\hline & & $\mathrm{BE} \times \operatorname{Irr}$ & 109.51 & 1 & 109.51 & 0.30 & 0.59 \\
\hline \multirow[t]{3}{*}{ Pulse, min } & & $\mathrm{BE}$ & 144.87 & 1 & 144.87 & 7.48 & $0.01^{* *}$ \\
\hline & & Irr & 102.68 & 1 & 102.68 & 0.60 & 0.45 \\
\hline & & $\mathrm{BE} \times \mathrm{Irr}$ & 3.07 & 1 & 3.07 & 0.16 & 0.69 \\
\hline
\end{tabular}

Summary of results of ANCOVA for all craving variables. In the results shown here, age was treated as a covariant. BE $=\mathrm{Baseline} / \mathrm{after}$ cue exposure; Irr $=$ irritability. ${ }^{*} \mathrm{p}<0.05 ; * * \mathrm{p}<0.01$.

The results of the VAS are somehow mixed. On 'I have a craving for alcohol' (VAS-crave), both irritability and cue exposure exerted a significant main effect; the F values are $5.43(\mathrm{p}=0.03)$ and $4.23(\mathrm{p}=0.05)$, respectively. The interactive effect of irritability and cue exposure on 'I intend to drink alcohol' (VAS-intent) of the VAS also reaches a significance level of $0.05[\mathrm{~F}(1,29)=4.22]$ (fig. 2). Furthermore, the main effect of irritability on VAS-enjoy, VAS-drink, VAS-depre, and the VAS-nerv of the VAS likewise reveals a trend towards significance. Similar to the outcomes of the ACQ, the high-irritable subjects reported a higher level of craving for alcohol, intention to alcohol ingestion, joy of drinking alcohol, possibility to use alcohol, depression, and nervousness than did their low-irritable counterparts, regardless of the presence of alcohol cues. The intentions of both groups to use alcohol decreased (high-irritable group) or remained barely at the same level (low-irritable group) after confrontation with alcohol cues; however, the craving for alcohol was elevated in subjects with high irritability, while that of low-irritable alcohol dependents was slightly reduced. After cue exposure, low-irritable alcohol patients tended to feel slightly more depressed compared with baseline, but high-irritable ones felt much more de- 
pressed. However, the enjoyment of drinking alcohol, the possibility to use alcohol again, and nervousness increased in the high-irritable group, whereas those of the low-irritable one decreased.

Regarding the impact of irritability on heart rate, neither the main effect nor its interaction with cue exposure was significant. Nevertheless, exposure to alcohol stimuli led to an elevation of heart rate in both groups of subjects with a similar magnitude $(F=7.48 ; p=0.01)$.

\section{Discussion}

Generally speaking, the outcomes of this study provide preliminary support for Gilbert's [1997] Situation-TraitAdoptive-Response Model and that of Wetterling et al. [1996]; both indicate personality as an interceptive factor that might influence craving. Alcohol inpatients with a different inclination to irritability reacted psychologically as well as physiologically differently towards alcoholrelated stimuli. The fact that the presentation of alcoholic beverage could provoke the subjectively perceived desire to drink alcohol [Cooney et al., 1997] was also partly supported by our results; however, in our study, provocative effects of alcohol cues were observed only in heart rate and its interactions with irritability on 2 aspects of craving [drinking intention (VAS-intent) and 'control over alcohol intake' (COMP)]. The small discrepancy between the outcomes of the ACQ and those of the VAS in this study possibly resulted from a different conceptualization of both measuring instruments. A complex dimension of the ACQ contains 3 questions, while a question of the VAS presents exclusively a simple, however, ambiguous concept.

As irritability and aggressivity significantly correlate with each other $(r=0.41, p=0.02)$, the present results correspond with our earlier report concerning the relationship between aggressivity and craving [Chiang et al., 2001]. A comparison between the results is summarized in table 7. Both characteristic dimensions of alcoholics showed impacts on almost the same aspects of craving (PURP, EMOT, XPCT of the ACQ and VAS-intent, VAS-crave of the VAS), however, to significantly different degrees. Individual inputs of both personality features were also observed. Both aggressivity and irritability interacted with VAS-intent of the VAS; however, the interaction between aggressivity and 'intend to drink alcohol soon' (VAS-intent) is much stronger than that between irritability and VAS-intent ( $p=0.001$ vs. 0.05 ). Both traits exhibited impacts on the PURP and XPCT dimension of

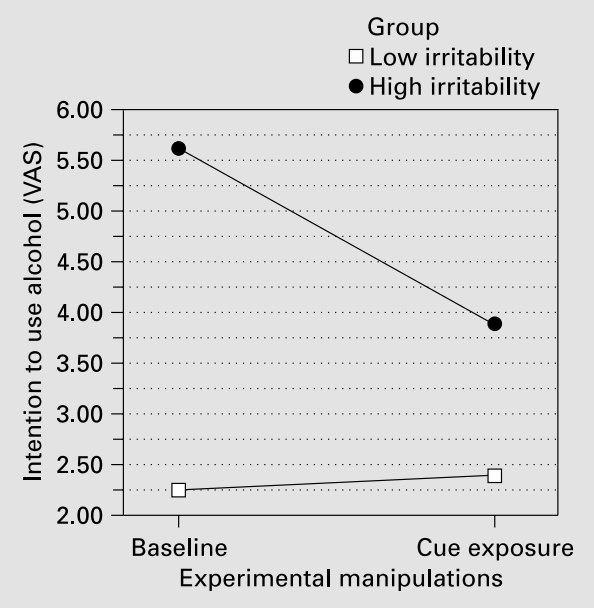

Fig. 2. The interactive effect between irritability and cue exposure on the question 'I intend to drink alcohol' of the VAS. The result shown here is modified by using the factor 'age' as a covariant.

the ACQ; nonetheless, the significance levels of aggressivity are higher (PURP: $p=0.001$ vs. 0.003 ; XPCT: $p=$ 0.003 vs. 0.02 ); PURP involves feelings 'to be going to drink alcohol as soon as possible' and XPCT concerns 'the sensed tension reduction, if they used alcohol after confrontation with alcohol cues'. Both personality dispositions revealed significant main effects on EMOT of the ACQ; however, the one of irritability is stronger $(\mathrm{p}=$ $0.005)$ than that of aggressivity $(p=0.01)$. In addition, irritability influenced COMP of the ACQ and VAS-crave of the VAS without interacting with alcohol cues, while aggressivity significantly interacted with alcohol cues without revealing any significant main effect on craving for alcohol (VAS-crave). Finally, the effects of alcohol cue presentation on VAS-intent, VAS-crave of the VAS and the heart rate varied with involved propensity; if aggressivity was involved, the impacts of confrontation with alcohol stimuli became stronger. Taken together, irritability seems to have stronger influences on the emotional reaction to alcohol cues, whereas aggressivity appears to exhibit more impacts on the aspects of craving, emphasizing action orientation.

The results of this study seem to fit well in the frame of various prominent theories of craving/alcoholism, such as Tiffany's [1990, 1992, 1995] cognitive craving theory, classical conditioning, operant conditioning, and selfmedication hypothesis. 
Table 7. A comparison of the important results (ANCOVA) from aggressivity and irritability: the main effects of aggressivity/irritability and their interactions with the presence of alcohol cues on craving for alcohol

\begin{tabular}{|c|c|c|c|c|c|c|}
\hline \multirow[t]{2}{*}{ Questionnaire } & \multirow[t]{2}{*}{ Dimension } & \multirow[t]{2}{*}{ Source } & \multicolumn{2}{|c|}{ Aggressivity } & \multicolumn{2}{|c|}{ Irritability } \\
\hline & & & $\mathrm{F}$ & $\mathrm{p}$ & $\mathrm{F}$ & $\mathrm{p}$ \\
\hline \multirow[t]{12}{*}{ ACQ } & \multirow[t]{3}{*}{ EMOT } & $\mathrm{BE}$ & & n.s. & & n.s. \\
\hline & & agg/irr & 7.32 & $0.01^{* *}$ & 9.54 & $0.005^{* * *}$ \\
\hline & & $\mathrm{BE} \times$ agg/irr & & n.s. & & n.s. \\
\hline & \multirow[t]{3}{*}{ COMP } & $\mathrm{BE}$ & & n.s. & & n.s. \\
\hline & & agg/irr & & n.s. & & n.s. \\
\hline & & $\mathrm{BE} \times$ agg/irr & & n.s. & 5.11 & $0.05^{*}$ \\
\hline & \multirow[t]{3}{*}{ PURP } & & & n.s. & & \\
\hline & & agg/irr & 14.26 & $0.001 * * * *$ & 10.55 & $0.003^{* * *}$ \\
\hline & & $\mathrm{BE} \times \mathrm{agg} / \mathrm{irr}$ & & n.s. & & n.s. \\
\hline & \multirow[t]{3}{*}{ XРCT } & & & n.s. & & n.s. \\
\hline & & agg/irr & 10.67 & $0.003^{* * *}$ & 6.03 & $0.02 *$ \\
\hline & & $\mathrm{BE} \times$ agg/irr & & n.s. & & n.s. \\
\hline \multirow[t]{6}{*}{ VAS } & \multirow[t]{3}{*}{ VAS-intent } & $\mathrm{BE}$ & 9.72 & $0.004^{* * *}$ & 5.59 & $0.03^{*}$ \\
\hline & & agg/irr & & n.s. & & n.s. \\
\hline & & $\mathrm{BE} \times \mathrm{agg} / \mathrm{irr}$ & 13.30 & $0.001 * * * *$ & 4.22 & $0.05^{*}$ \\
\hline & \multirow[t]{3}{*}{ VAS-crave } & $\mathrm{BE}$ & 10.31 & $0.003^{* * *}$ & 4.23 & $0.05^{*}$ \\
\hline & & agg/irr & & n.s. & 5.43 & $0.03^{*}$ \\
\hline & & $\mathrm{BE} \times$ agg/irr & 6.85 & $0.01 * *$ & & n.s. \\
\hline \multirow[t]{3}{*}{ Heart rate } & \multirow[t]{3}{*}{ pulse/min } & $\mathrm{BE}$ & 8.54 & $0.007 * *$ & 7.48 & $0.01^{* *}$ \\
\hline & & agg/irr & & n.s. & & n.s. \\
\hline & & $\mathrm{BE} \times$ agg/irr & & n.s. & & n.s. \\
\hline
\end{tabular}

$\mathrm{BE}=$ Baseline/after cue exposure; agg = aggressivity; irr = irritability; $\mathrm{BE} \times$ agg/irr $=$ interaction between $\mathrm{BE}$ and aggressivity/irritability; ${ }^{*} \mathrm{p}<0.05 ;{ }^{* *} \mathrm{p}<0.01 ; * * * \mathrm{p}<0.005 ;{ }^{* * * *} \mathrm{p}<0.001 ;$ n.s. $=$ not significant $(\mathrm{p}>0.05)$.

In the results shown here, age was treated as a covariant.

First, all our subjects still experienced craving and did not have total control over alcohol ingestion at baseline and after exposition to alcohol cues; craving develops when alcohol intake is blocked [Tiffany, 1990, 1992, 1995]. The subjects were hospitalized and were not allowed to consume alcohol during the experiment and treatment. It might have raised an approach-avoidance conflict in them, as they were confronted with their favorite beer visually and olfactorily in a laboratory of a hospital. They could have tried to stop thinking of alcohol-related things. Thus, they reported a strength of alcohol craving ranging from 18 to 37 and a control over alcohol use from 20 to 84, if the highest level of craving/control is regarded as 100 . Even 1 week after physical withdrawal, none of the subjects was 100\% free of alcohol craving and sensed $100 \%$ of control over alcohol consumption during confrontation with alcohol stimuli.

Second, the high irritable group exhibited significantly stronger negative emotions (STAI, POMS, VAS-nerv,
VAS-depre) and less behavior inhibition (VAS-drink) with regard to alcohol consumption. Negative affects like anxiety, nervousness, and depression could play a role in the development of craving [Mathew et al. 1979; Wetterling et al., 1996; Cooney et al., 1997; Willner et al., 1998]. Greeley et al. [1992] even saw depressed affect as a predictor of increased alcohol craving. In line with the self-medication hypothesis, highly anxious individuals consume alcohol to reduce their anxiety more frequently [Cox et al., 1990; George et al., 1990]. The high-irritable alcoholics could have more frequently used alcohol to reduce their negative affects and therefore have had more chances to negatively reinforce the link between alcohol use and negative affects (classical conditioning); correspondingly, the probabilities for them to consume alcohol again would be enhanced if they experience negative affects (operant conditioning). However, the perceived self-control over alcohol use of the high-irritable group, in contrast to that of the low-irritable alcoholics, was contra- 
dictory to their experienced craving. Such a cognitive dissonance in alcoholic inpatients was described by Lipscomb and Nathan [1980] two decades ago and has recently been reindicated by Carter and Tiffany [1999]. In this study, the tendency to deny the occurrence of craving was even more conspicuous when the results before and after exposure to alcohol cues were compared, particularly in the high-irritable alcoholics. Struggling with an approach-avoidance conflict ('want to drink' and 'should not drink') could be another explanation for them to experience stronger craving than the low-irritable alcohol addicts according to Tiffany's [1990, 1992, 1995] cognitive craving theory.

Finally, enhanced heart rate was repeatedly described as a typical cue reactivity to exposed alcohol stimuli in a number of studies [e.g. Kaplan et al., 1983; McCusker and Brown, 1991; Kaplan et al., 1985; Cooney et al., 1997; Glautier and Drummond, 1994; McCaul et al., 1989a, 1989b; Stormark et al., 1995], although their experimental designs, including cues, induction methods, and features of participants differ from one another. Rajan et al. [1998] even deemed it as a reliable indicator of cue reactivity. Nevertheless, the studies of Pomerleau et al. [1983], Eriksen and Goetestam [1984], and Greeley et al. [1993] implicate either no elevation or reduction. Our present findings were consistent with those of Kaplan and the other research groups. Both high- and low-irritable alcoholic patients similarly reacted to cue exposure with accelerated heart rate. Nonetheless, a HHR paradigm used in this study could overestimate heart rate, though additional observation throughout the experiment did not reveal overt behavioral differences between baseline and cue exposure.

In sum, the outcomes of this study indicate the salience of irritability as a disposition in experimentally induced craving in recently detoxified alcoholics. The impact of alcohol cues seems to be limited to heart rate and the perceived control over alcohol. How craving actually interacts with the irritable disposition of the alcoholics after discharge from the clinic requires further studies in a more genuine 'natural' setting. However, the results of this study might offer some indications to devise more individual coping strategies to deal with high-risk relapse situations for alcoholics as well as to develop more sophisticated medical treatment. Cue exposure to alcohol stimuli has already been incorporated in many alcohol treatment settings [Scharfenberg and Soyka, 2000] and studies on the interaction between cue exposure, craving and relapse may be of great interest for alcohol research in the near future.

\section{Acknowledgement}

This study was supported by the Hanns-Seidel Foundation.

\section{References}

Anton RF: What is craving? Models and implications for treatment. Alcohol Res Health 1999; 23:165-173.

American Psychiatric Association: Diagnostic and Statistical Manual of Mental Disorders, ed 4.. Washington, American Psychiatric Association, 1994.

Ausubel DP: Methadone maintenance treatment: The other side of the coin. Int J Addict 1983; 18:851-862.

Brent DA, Bridge J, Johnson BA, Conolly JC: Suicidal behavior runs in families: Controlled family study of adolescent suicidal victims. Arch Gen Psychiatry 1996;53:1145-1152.

Buss AH, Durkee A: An inventory for assessing different kinds of hostility. J Consult Psychol 1957;21:343-349.

Carter BL, Tiffany ST: Meta-analysis of cue-reactivity in addiction research. Addiction 1999; 94:327-340.

Ciccocioppo R: The role of serotonin in craving: From basic research to human studies. Alcohol Alcohol 1999;34:244-253.
Chiang SSW, Schuetz CG, Soyka M: Role of aggressivity on reactivity and craving before and after cue exposure in recently detoxified alcoholics: Results from an experimental study. Eur Addict Res 2001;1:184-192.

Cloninger CR, Bohman M, Sigvardsson S: Inheritance of alcohol abuse. Cross-fostering analysis of adopted men. Arch Gen Psychiatry 1981;38: 861-868.

Cloninger CR, Sigvardsson S, Bohman M: Childhood personality predicts alcohol abuse in young adults. Alcohol Clin Exp Res 1988;12: 494-505.

Cooney NL, Litt MD, Morse PA, Bauer LO Gaupp L: Alcohol cue reactivity, negative-mood reactivity, and relapse in treated alcoholic men. $\mathbf{J}$ Abnorm Psychol 1997;106:243-250.

Cottler LB, Price RK, Compton WM, Mager DE: Subtypes of adult antisocial behavior among drug abusers. J Nerv Ment Dis 1995;183:154161 .

Cox BJ, Norton GR, Swinson RP, Endler NS: Substance abuse and panic-related anxiety: A critical review. Behav Res Ther 1990;28:385-393.
Eriksen L, Gotestam KG: Conditioned abstinence in alcoholics: A controlled experiment. Int J Addict 1984; 19:287-294.

Flannery BA, Roberts AJ, Cooney N, Swift RM, Anton RF, Rohsenow DJ: The role of craving in alcohol use, dependence, and treatment. Alcohol Clin Exp Res 2001;25:299-308.

George DT, Nutt DJ, Dwyer BA, Linnoila M: Alcoholism and panic disorder: Is the comorbidity more than coincidence? Acta Psychiatr Scand 1990;81:97-107.

Gilbert DG: The situation $x$ trait adaptive response (STAR) model of drug use, effects, and craving. Hum Psychopharmacol 1997;12(suppl 2):S89S102.

Glautier S, Drummond DC: Alcohol dependence and cue reactivity. J Stud Alcohol 1994;55: 224-229.

Greeley JD, Swift W, Heather N: To drink or not to drink? Assessing conflicting desires in dependent drinkers in treatment. Drug Alcohol Depend 1993;32:169-179. 
Greeley JD, Swift W, Heather N: Depressed affect as a predictor of increased desire for alcohol in current drinkers of alcohol. Br J Addict 1992; 87:1005-1012.

Gunderson JG, Philips KA: Personality Disorders. Baltimore, Williams \& Wilkins, 1995.

Kaplan RF, Cooney NL, Baker LH, Gillespie RA, Meyer RE, Pomerleau OF: Reactivity to alcohol-related cues: Physiological and subjective responses in alcoholics and nonproblem drinkers. J Stud Alcohol 1985;46:267-272.

Kaplan RF, Meyer RE, Stroebel CF: Alcohol dependence and responsivity to an ethanol stimulus as predictors of alcohol consumption. Br J Addict 1983;78:259-267.

Kornadt HJ: Buss-Durkee Hostility-Guilt Inventory - German version; in Buss AH, Durkee A (eds): Aggressionsmotiv und Aggressionshemmung. 1. Empirische und theoretische Untersuchungen zu einer Motivationstheorie der Aggression und zur Konstruktvalidierung eines Aggressions-TAT und andere aggressionsrelevante Verfahren. Bern, Huber, 1982, vol 2, pp $138-141$.

Laux L, Glanzmann P, Schaffner P, Spielberger CD: STAI: State-Trait Anxiety Inventory German Version. Weinheim, Beltz, 1981.

Kozlowski LT, Mann RE, Wilkinson DA, Poulos CX: 'Cravings' are ambiguous: Ask about urges or desires. Addict Behav 1989;14:443-445.

Lewis CE, Robins L, Rice J: Association of alcoholism with antisocial personality in urban men. $\mathrm{J}$ Nerv Ment Dis 1985;173:166-174.

Lipscomb TR, Nathan PE: Blood alcohol level discrimination. The effects of family history of alcoholism, drinking pattern, and tolerance. Arch Gen Psychiatry 1980;37:571-576.

Markou A, Weiss F, Gold LH, Caine SB, Schulteis G, Koob GF: Animal models of drug craving. Psychopharmacology (Berl) 1993;112:163182.

Mathew RJ, Claghorn JL, Largen J: Craving for alcohol in sober alcoholics. Am J Psychiatry 1979; 136:603-606.

Mega MS, Cummings JC, Fionello T, Gornheim $\mathrm{JC}$ : The spectrum of behavioral changes in Alzheimer's disease. Neurology 1996;46:130-142.

Meyer RE: Craving: What can be done to bring the insights of neuroscience, behavioral clinical science into synchrony. Addiction 2000;95: 219-227.

McCaul ME, Turkkan JS, Stitzer ML: Conditioned opponent responses: Effects of placebo challenge in alcoholic subjects. Alcohol Clin Exp Res 1989a; 13:631-635.

McCaul ME, Turkkan JS, Stitzer ML: Psychophysiological effects of alcohol-related stimuli. 1. The role of stimulus intensity. Alcohol Clin Exp Res 1989b;13:386-391.

McCusker CG, Brown K: The cue-responsivity phenomenon in dependent drinkers: 'Personality' vulnerability and anxiety as intervening variables. Br J Addict 1991;86:905-912.
McNair DM, Lorr M, Dropplemann LF, Biehl B, Dangel S: POMS: Profile of Mood States - German adaption; in Collegium Internationale Psychiatriae Scalarum (eds): Internationale Skalen für Psychiatrie. Weinheim, Beltz, 1981.

Moss HB, Yao JK, Panzak GL: Serotonergic responsivity and behavioral dimensions in antisocial personality disorder with substance abuse. Biol Psychiatry 1999;28:325-338.

Naranjo CA, Kadlec KE: Possible pharmacological probes for predicting and preventing relapse in treated alcoholics. Alcohol Alcohol Suppl 1991; 1:523-526.

Nerviano VJ, Gross HW: Personality types of alcoholics on objective inventories. A review. J Stud Alcohol 1983;44:837-851.

Newlin DB: A comparison of drug conditioning and craving for alcohol and cocaine. Recent Dev Alcohol 1992;10:147-164.

Norregaard J, Tonnesen P, Petersen L: Predictors and reasons for relapse in smoking cessation with nicotine and placebo patches. Prev Med 1993;22:261-271.

Pickens RW, Johanson CE: Craving: Consensus of status and agenda for future research. Drug Alcohol Depend 1992;130:127-131.

Pomerleau OF, Fertig J, Baker L, Cooney N: Reactivity to alcohol cues in alcoholics and nonalcoholics: Implications for a stimulus control analysis of drinking. Addict Behav 1983;8:110 .

Potgieter AS, Deckers F, Geerlings P: Craving and relapse measurement in alcoholism. Alcohol Alcohol 1983:34:254-260.

Prescott CA, Neale MC, Corey LA, Kendler KS: Predictors of problem drinking and alcohol dependence in a population-based sample of female twins. J Stud Alcohol 1997;58:167-181.

Preuss UW, Schuetz C, Koch J, Soyka M: Psychometrische Erfassung von subjektivem Craving mit der Obsessive Compulsive Drinking Scale (OCDS) und Einflüsse von Befindlichkeit und Persönlichkeit. Suchtmed 1999;1:33-38.

Rajan I, Murthy PJ, Ramakrishnan AG, Gangadhar BN, Janakiramaiah N: Heart rate variability as an index of cue reactivity in alcoholics. Biol Psychiatry 1998;43:544-546.

Renson GJ, Adams JE, Tinklenberg JR: Buss-Durkee assessment and validation with violent versus nonviolent chronic alcohol abusers. J Consult Clin Psychol 1978;46:360-361.

Robins LN: The adult development of the antisocial child. Semin Psychiatry 1970;2:420-434.

Scharfenberg CD, Soyka M: Alkohol-Exposition als verhaltenstherapeutischer Ansatz bei ambulanten Entwöhnungstherapien: Theoretischer Hintergrund und Falldarstellung. Suchtmed 2000;2:121-126.

Schuetz CG, Koch J, Preuss U, Soyka M: Reliability and validity of the German version of the 47-item Craving Questionnaire and the 49item Addiction Research Center Inventory. Build Int Res Infrastruct Field Drug Abuse. Nashville, June 1997.
Sher KJ, Trull TJ: Personality and disinhibitory psychopathology: Alcoholism and antisocial personality disorder. J Abnorm Psychol 1994; 103:92-102.

Sinha R, O'Malley SS: Craving for alcohol: Findings from the clinic and the laboratory. Alcohol Alcohol 1999;34:223-230.

Snaith RP, Taylor CM: Irritability: Definition, assessment and associated factors. Br J Psychiatry $1985 ; 147: 127-136$.

Stormark KM, Laberg JC, Bjerland T, Nordby H, Hugdahl K: Autonomic cued reactivity in alcoholics: The effect of olfactory stimuli. Addict Behav 1995;20:571-584.

Svanborg P, Gustavsson PJ, Mattila-Evenden M, Asberg M: Assessment of maladaptiveness: A core issue in the diagnosing of personality disorders. J Personal Disord 1999;13:241-256.

Tarter RE, Blackson T, Brigham J, Moss H, Caprara GV: The association between childhood irritability and liability to substance use in early adolescence: A 2-year follow-up study of boys at risk for substance abuse. Drug Alcohol Depend 1995;39:253-261.

Tiffany ST: A cognitive model of drug urges and drug-use behavior: Role of automatic and nonautomatic processes. Psychol Rev 1990;97: 147-168.

Tiffany ST: A critique of contemporary urge and craving research: Methodological, psychometric, and theoretical issues. Addict Behav 1992; 15:123-139.

Tiffany ST: The role of cognitive factors in reactivity to drug cues; in Drummond DC, Tiffany ST, Glautier S, Remington B (eds): Addictive Behaviour: Cue Exposure Theory and Practice. Chichester, Wiley, 1995, pp 137-165.

Tiffany ST, Singleton EG, Henningfield JE, Heisman SJ, Douglas TE: Multidimensional aspects of craving for alcohol. 57th Annu Sci Meet, 1995.

Tomori M: Personality characteristics of adolescents with alcoholic parents. Adolescence 1994;29:949-959.

Verheul R, van-den-Brink W, Koeter MW: Temporal stability of diagnostic criteria for antisocial personality disorder in male alcohol dependent patients. J Personal Disord 1998;12:316-331.

Wetterling T, Veltrup C, Junghanns K: Craving an adequately defined concept? Fortschr Neurol Psychiatr 1996;64:142-152.

Willner P, Benton D, Brown E, Cheeta S, Davies G, Morgan J, Morgan M: 'Depression' increases 'craving' for sweet rewards in animal and human models of depression and craving. Psychopharmacology (Berl) 1998;136:272-283.

Wittchen HU, Zaudig M, Fydrich T: SKID-I/II: Users Guide for the Structured Clinical Interview for DSM-IV - German Modified Version. Göttingen, Hogrefe, 1997.

World Health Organization: Internationale Klassifikation psychischer Störungen ICD-10. Kapitel V (F) Forschungskriterien. Bern, Huber, 1994. 